\title{
Inclusive Instructional Practices: Course Design, Implementation, and Discourse
}

\author{
Shima Salehi ${ }^{1 *}$, Cissy J. Ballen ${ }^{2}$, Gloriana Trujillo ${ }^{3}$ and Carl Wieman ${ }^{4}$ \\ ${ }^{1}$ Graduate School of Eduction, Stanford University, Stanford, CA, United States, ${ }^{2}$ Department of Biological Sciences, Auburn \\ University, Auburn, AL, United States, ${ }^{3}$ Center for Teaching and Learning, Stanford University, Stanford, CA, United States, \\ ${ }^{4}$ Department of Physics, Stanford University, Stanford, CA, United States
}

OPEN ACCESS

Edited by:

Subramaniam Ramanathan, Nanyang Technological University, Singapore

Reviewed by: Julio Ciro Benegas, National University of San Luis, Argentina

Bryan Dewsbury, Florida International University, United States

*Correspondence: Shima Salehi salehi@stanford.edu

Specialty section: This article was submitted to STEM Education,

a section of the journal Frontiers in Education

Received: 03 September 2020 Accepted: 17 September 2021 Published: 01 October 2021

Citation:

Salehi S, Ballen CJ, Trujillo $G$ and Wieman C (2021) Inclusive Instructional Practices: Course Design, Implementation, and Discourse. Front. Educ. 6:602639. doi: 10.3389/feduc.2021.602639
As national efforts strive to make STEM more inclusive, it is important to identify instructional practices that maximize effective learning for all and provide students from different demographic and educational backgrounds equal opportunities to excel. Here, we present a guideline for inclusive instructional practices based on findings from 1) cognitive psychology about learning and memory, 2) social psychology about creating inclusive discourse, and 3) discipline-based education research (DBER) about effective learning practices in STEM higher education. Our aim is to promote equity across STEM education by providing researchers and instructors across different STEM fields with concrete suggestions for implementing inclusive instructional practices in their courses.

Keywords: stem education, inclusivity, equity, underrepresented students, instructional guideline

\section{INTRODUCTION}

Testing the effectiveness of instructional practices in undergraduate STEM requires empirical assessments across multiple disciplinary and institutional contexts (C. A. Brewer and Smith, 2011; National Academies of Sciences and Medicine, E, 2016). Investigations into student outcomes include comparisons of performance measures such as exam scores, final grades, concept inventory scores, student behaviors, or affective factors (e.g., the extent to which students identify as scientists) (see National Research Council, 2012 for overview of different measures used in DBER research). Over one hundred studies have examined the impacts of evidencebased learner-centered pedagogy, also referred to as active learning, on measures of aggregated class performance outcomes (Freeman et al., 2014). However, of these studies, few focused on the effects of active learning pedagogies on underrepresented students in STEM specifically, or have considered the reduction or closure of performance gaps as stand-alone measures worthy of explicit focus (e.g., Haak et al., 2011; Ballen et al., 2017; Casper et al., 2019; Theobald EJ. et al., 2020). Under-represented groups in STEM are those whose representation in STEM fields is smaller than their actual representation in the society (e.g., African-Americans constitute $13 \%$ of US population but they earned only up to $8 \%$ of STEM B.S. degrees in the last 20 years (Rivers, 2017)). Studies that explicitly tracked the performance of under-represented students showed that across different STEM disciplines, active learning pedagogies had a disproportionate positive impact on their performance (Theobald EJ. et al., 2020). However, these studies were still limited in number and context. Therefore, as one of the next frontiers of STEM education, it is incumbent upon the STEM education community to examine and identify inclusive instructional practices in order to support national efforts to promote and retain those historically underrepresented in STEM. We consider inclusive instructional practices as a collection of historically-, socially-, cognitively-, and culturally- 
sensitive instructional practices implemented in classrooms in order to create equitable learning opportunities for students from different demographic and educational backgrounds. For example, for designing historically-sensitive instructional practices in the United States, one ought to consider the fact that a number of demographic groups were deprived of educational resources over several generations. These historical injustices led to current circumstances in which some demographics are more likely to live in neighborhoods and to attend K-12 schools which are under-resourced, leading to lower academic preparation as students enter higher education (Chetty and Hendren, 2018; Fahle et al., 2020).

We provide a guide for inclusive instructional practices using theoretical and empirical findings from diverse fields. Specifically, we draw from cognitive psychology to discuss learning and memory; social psychology to inform our thinking on creating inclusive discourse; and discipline-based education research to apply effective instructional practices in higher education STEM. There are theoretical reasons for believing the efficacy of these previous findings would be transferrable across different STEM fields, even when empirical studies are limited. We have organized this inclusive teaching practices guide around three major aspects of a STEM course: design, implementation, and classroom discourse. The individual practices fall largely into two groups, as we have labelled: 1) General Category [GC]: generally effective teaching practices which have been shown to benefit all students including underrepresented students; and 2) Targeted Category [TC]: effective teaching practices which particularly benefit underrepresented students by addressing specific aspects that serve as barriers to academic success that are unique to underrepresented students (Schwartz et al., 2016). Targeted practices do not benefit underrepresented students by hindering the performance of over-represented students (Powers et al., 2016), but rather, the extent of their positive effects is larger for underrepresented students, as they target the barriers that are more pronounced for these students. Both categories of inclusive instructional practices are required to create an equitable learning environment which helps students from different backgrounds to thrive, and some practices may span both categories.

\section{GUIDELINE FOR INCLUSIVE INSTRUCTIONAL PRACTICES}

\section{(1) Course Design:}

- [GC] Have all students understand what they need to do to succeed, regardless of their background. The absence of this information in course materials rewards students who are aware of the "hidden curriculum," who are better prepared for college courses, and are more familiar with the culture, expectations, and assessment methods of higher education (Anyon, 1980; Margolis, 2001; Smith, 2013; Basyiruddin, 2020). For example, effective study habits, which encompass the strategies students use to learn, understand, and retain course content, can be underdeveloped among incoming
STEM students (Blasiman et al., 2017). Students (and instructors) commonly rely on ineffective study strategies aimed at short-term goals, such as passing an exam, rather than meaningful understanding of the material (Kornell and Bjork, 2007). Clarifying how to study effectively and actively will encourage success for all students, rather than those who entered the course with existing knowledge of the material or advanced study habit strategies.

- [GC] Have all students understand different components of their course grade, their weights, and how the final course grade is calculated to ensure grades are providing meaningful and effective feedback to students (Quinn, 2013; Feldman, 2018). Lack of a clear grading scheme makes it challenging for students to use the grade they receive in each component of the course as a measure of their learning, and to prioritize investment on learning different aspects of the course. For example, curving grades without clarifying the scheme renders the scores uninterpretable to students, particularly those less familiar with the curving practice. This practice discourages these students as they underestimate their performance in the course (Seymour and Hunter, 2019).

- [GC] Have all students recognize the resources available to them, and how they can best use each of these resources. Without clearly enumerating all the available resources and how students can use them, resources will be utilized by students who are more aware of the university environment and better prepared for college courses, particularly STEM courses (Cotten and Wilson, 2006). For example, students from different backgrounds have different ideas as to what is meant by "instructor office hours", and how they can benefit from them. For students who did not have office hours in their precollege education may perceive instructor office hours as a place for them to demonstrate what they have already learned, as opposed to a place for instructors to provide additional individual help with what they have not already learned (Jack, 2019).

- [GC] Provide supplementary materials and instructions that will support students with gaps in their preparation, as well as tools to allow students and instructors to identify such gaps. Communicate in advance when students should seek out and use these resources (Rath et al., 2007). Many STEM courses are based on pre-requisite foundational knowledge. For introductory courses, this knowledge should be provided in high school courses. However, significant gaps in the quality and quantity of high school courses equate to gaps in foundational knowledge (Reardon et al., 2019). Previous work shows gaps in incoming preparation is the main reason for demographic performance gaps in introductory STEM courses (Salehi et al., 2019; Salehi et al., 2020). Without providing supplementary materials to address these gaps in preparation, the STEM courses tend to target the well-prepared students and discriminate against students who came from under-resourced schools with regard to STEM education (Seymour and Hunter, 2019). 
- Note: Supplementary materials can be offered in different formats. For example, instructors can: 1) suggest a companion course for students to complete alongside the main course (Fullilove and Treisman, 1990; Batz et al., 2015); 2) dedicate one of the instructor office hours or TA sections to less prepared students; 3 ) offer an explicit list of external resources (e.g., free online educational videos) that cover course pre-requisites. In providing these resources, one should be mindful of efficiency of supplemental materials in order to balance between inside- and outside-class workload. Many of the students without proper incoming preparation are from less-privileged backgrounds and may work a paid job to cover the cost of their education and/or support their family. This makes their time outside classroom more limited.

- [GC] Design instruction based on the "deliberate practice" approach. As Ericsson et al. (1993) showed in different contexts, acquiring expertise requires: 1) decomposing expertise into subskills, acknowledging that some subskills must be mastered before learning other ones; 2) designing learning activities that directly address each of those subskills through practice; 3) engaging learners in those activities; 4) providing specific, timely, nonthreatening, and actionable feedback about learner's performance; 5) allowing the learner to repeat the activity using the feedback to improve that subskill. To design the course based on deliberate practice approach in STEM courses, the instructor can:

$\bigcirc$ Clarify and decompose the learning goals to the point that corresponding learning activities directly address each goal. Identify more challenging learning goals and dedicate more resources to them.

- Note: this is particularly an important activity for the instructor to engage in as they prepare their course materials, as it helps them overcome their "expert blind spots" of difficult topics that they may overlook.

O Provide students with frequent practice and feedback opportunities. Design learning activities that the individual can engage in between lecture sessions to practice those learning goals (Wood et al., 1994; Willoughby et al., 2000; Preszler et al., 2007; Thomas and McDaniel, 2007; Dunlosky et al., 2013). Without the opportunity to repeat and improve, less prepared students will struggle compared to those who have received more academic preparation.

- [GC] Explicitly align learning activities that students complete in class with their formal assessments. Consequential, high-stakes exams are not the time to test more complex questions than what students have been exposed to in class, though research has never explored the extent to which instructors assess this way (Morris et al., 1977; McDaniel et al., 1978; Ericsson et al., 1993; Morgan et al., 2007; Thomas and McDaniel, 2007; Wormald et al., 2009; Jensen et al., 2014). Alignment will provide students with different levels of academic preparation more equal opportunity to study effectively and perform well on tests. The mismatch between cognitive difficulty of the assessments and learning activities students engage in during the course (e.g., homework) mean students have to "read the instructor's mind" to prepare for exams. Underprepared students are at a disadvantage if assessed this way, particularly as they may often come from different backgrounds and cultures than the instructor. If the course learning activities match the course assessments, then student investment in these activities will help their performance on the assessments. The mismatch, on the other hand, leads to performance on assessments that is more reflective of students' prior preparation (and/or creative use of resources to which select students have access) than of knowledge and mastery of material from class.

\section{(2) Course Implementation:}

- [GC] Check that all students clearly see how each learning activity maps to a specific learning goal that defines in operational terms what they should be able to do. This will benefit students by providing a roadmap for monitoring their own learning and understanding which resources to use to address challenging material.

- [GC] Include frequent low stakes formative assessments/ quizzes that give students (and the instructor) feedback about student learning. Feedback is essential for students to improve their learning and for instructors to adapt their teaching. Using various formative assessment methods during class, such as polling tools or worksheets, provides frequent feedback to students and instructors about how well students are understanding the topics covered in lecture sessions.

- [TC] After communicating the course syllabus and roadmaps to success in the course, survey the students for the challenges they expect to encounter in the course, and work with them on finding support and/or accommodations where suitable (Meaders et al., 2020).

- [TC] Actively reach out to students who indicate performance struggles and explore how you can help them.

- [GC and TC] Encourage supportive and educationally productive group work in class. Set norms for interactions during group work to avoid dominance of individuals, and ensure every student is comfortable contributing. Group work benefits students' learning if done properly; if not deliberately structured, it can be unpleasant for some students and generally ineffective. To encourage successful group work:

$\bigcirc$ Create well-defined activities for groups that include both individually-completed and group-completed components.

$\bigcirc$ Randomly assign tasks to ensure the rotation of roles in groups such as who reports back from each group or who records notes. Although "cold calling" on individuals to answer questions about the work has been shown to be more equitable and improve performance of at-risk groups, it can be stressful on individuals (Dallimore 
et al., 2013; Cooper et al., 2018). This can be reduced by calling on individuals to present "what your group thinks", rather than their individual answer.

Intervene if individuals are dominating the group interactions or interrupting others, or if some members are excluded from the group discussions.

O Provide students with an opportunity to think individually before group activities or answering in-class polls (Rowe, 1969; Nicol and Boyle, 2003; Nielsen et al., 2012).

- [TC] Consider the cost of learning technologies and resources required for your course and try to minimize and/or provide support for the cost as much as possible. For example: 1) choose a free desktop or mobile application or website (e.g., Poll Everywhere) for formative assessments instead of clickers, which cost money; 2) If any component of the course (e.g., textbook or assignment platforms) costs money, explore potential resources for students who need help to cover the costs and explicitly list those resources in the course syllabus.

\section{(3) Class Discourse:}

- [TC] Avoid language and examples that imply a particular group of students is the main audience of your course. For example, an instructor who apologizes for the price of the expensive textbook required for the class, but then encourages students to "just have your parents pay for it," is problematic for many reasons. Some students are paying for their own education, and many others are generally concerned about their finances (Harrison and Tanner 2018). In this example, the instructor's language is excluding those students and subtly communicating that their financial situation is of no concern to them. Spend time reflecting on the diverse backgrounds and experiences of your students and acknowledge this diversity in the class discourse.

- [TC] Emphasize the importance of an inclusive learning environment and the roles of the teaching team and students:

List expectations of how students should treat one another in class in order to foster an inclusive environment and encourage students to review and modify the expectations.

Call out unacceptable comments or behavior (see microaggressions below).

$\bigcirc$ Be open to learn from your students about your implicit biases and/or exclusive behaviors by providing them the platform to give feedback.

- [GC and TC] Work to encourage a growth mindset (Claro et al., 2016; Yeager et al., 2016). Avoid references to "talent", stress the overriding importance of focused effort to achieve mastery, and emphasize that this applies to everyone (LinSiegler et al., 2016). Beware the common conflation of "talented" with "privileged" and therefore educationally better prepared.

O Share your own personal challenges in mastering a topic, methods you found to overcome them, and general challenges and strategies to learn. This will emphasize expertise in STEM topics is not the product of inherent talent or intelligence, but rather the product of repeated and deliberate practice.

O [TC] Communicate your belief in students' capability to learn and succeed. Previous studies have shown this disproportionately benefits underrepresented students (Cohen et al., 1999).

O Emphasize hard work over innate ability (Aronson et al., 2002; Good et al., 2012), but also be sensitive to needs for the right kind of hard work. Remember that less prepared students may not know how to study effectively, and everyone benefits from explicit guidance.

$\bigcirc$ Emphasize errors as natural and instructional (Bell and Kozlowski, 2008). Explain not just the correct answers but the reasons why an answer is wrong and how to fix it, along with what can be learned from the wrong answer. Provide students with opportunities to "redo" so that in the process they learn from their errors and can improve their grades.

- [TC] Emphasize the responsibility of the instructor as a facilitator of students' growth and learning. Students are in class to learn new skills, not to show off previous skills (Canning et al., 2019).

- Be vigilant and willing to intervene in response to microaggressions aimed at a student (Harrison and Tanner 2018). Microaggressions are brief, sometimes subtle comments that put down others based on their perceived personal characteristics, such as gender, sexual orientation, or underrepresented status (Sue, 2010).

- Discourage students from contributing "questions" that are actually just attempts to show off, not actual questions on the course material. Instructors who reward this behavior likely discourage students who have meaningful questions from asking them, and may make students feel like they are inferior and do not belong; which is a consequence of the "question that is not a question".

\section{FUTURE DIRECTIONS IN INCLUSIVE STEM EDUCATION}

We hope the guideline presented here contributes to improving equitable STEM education by providing researchers and instructors with concrete actions for improving the inclusivity of their courses. While this guideline is not a comprehensive literature review, we offer practical suggestions based on previous works to promote inclusive instructional practices. We acknowledge that there remain many detailed research questions still to be explored. While previous research has shown active learning disproportionately benefits underrepresented students, future work will explore what particular components of active learning courses benefit underrepresented students, features define successful implementation, and through what mechanisms are these effective-and for whom?

Addressing these research objectives requires better measures of incoming student preparation, and better measures of learning within a class. These are critical factors that currently serve as limitations to research, if the objective is to measure learning in response to different instructional practices over the course of a semester. While obtaining accurate measures of preparation and 
knowledge is challenging, researchers can use multiple measures of content-specific assessments and concept inventories that are tailored to specific classrooms (Salehi et al., 2019). A second important advance needed in education research is to collect and analyze data that go deeper than simply the overall class level; to examine the dependencies across different demographic groups (e.g., Ballen, Salehi et al., 2017; Casper et al., 2019). For example, if the outcome of an instructional practice results in the relative underperformance of a group on the basis of, for example, gender or race/ethnicity, we should question the inclusiveness of the practice rather than question the capacity of the students. Third, instead of relying on broad descriptions such as "active learning" or "flipped classroom", researchers should report the instructional practices used in their study in much more detail, and with precision, including the details of implementation (Driessen et al., 2020). Detailed descriptions will power robust metareviews of active learning components that are inclusive. Fourth, there is a need to better understand the contextual factors that influence inclusiveness of instructional practices by testing them across disciplinary and institutional contexts (Kanim and Cid, 2020; Thompson et al., 2020). To achieve this requires expanding the pool of research subjects

\section{REFERENCES}

Anyon, J. (1980). Social Class and the Hidden Curriculum of Work. J. Educ. 162, 67-92. doi:10.1177/002205748016200106

Aronson, J., Fried, C. B., and Good, C. (2002). Reducing the Effects of Stereotype Threat on African American College Students by Shaping Theories of Intelligence. J. Exp. Soc. Psychol. 38, 113-125. doi:10.1006/jesp.2001.1491

Ballen, C. J., Wieman, C., Salehi, S., Searle, J. B., and Zamudio, K. R. (2017). Enhancing Diversity in Undergraduate Science: Self-Efficacy Drives Performance Gains with Active Learning. CBE Life Sci. Educ. 16 (4), ar56. doi:10.1187/cbe.16-12-0344

Basyiruddin, M. (2020). "Teaching Strategies as a Powerful Hidden Curriculum: A Review Study," in 3rd International Conference on Learning Innovation and Quality Education (ICLIQE 2019), February 5th, 2020. Surakarta, Indonesia. (Atlantis Press), 765-769.

Batz, Z., Olsen, B. J., Dumont, J., Dastoor, F., and Smith, M. K. (2015). Helping Struggling Students in Introductory Biology: A Peer-Tutoring Approach that Improves Performance, Perception, and Retention. CBE Life Sci. Educ. 14 (2), ar16. doi:10.1187/cbe.14-08-0120

Bell, B. S., and Kozlowski, S. W. (2008). Active Learning: Effects of Core Training Design Elements on Self-Regulatory Processes, Learning, and Adaptability. J. Appl. Psychol. 93, 296-316. doi:10.1037/0021-9010.93.2.296

Blasiman, R. N., Dunlosky, J., and Rawson, K. A. (2017). The what, How Much, and when of Study Strategies: Comparing Intended versus Actual Study Behaviour. Memory 25 (6), 784-792. doi:10.1080/09658211.2016.1221974

Brewer, C. A., and Smith, D. (2011). Vision and Change in Undergraduate Biology Education: A Call to Action. Washington, DC: American Association for the Advancement of Science.

Canning, E. A., Muenks, K., Green, D. J., and Murphy, M. C. (2019). STEM Faculty Who Believe Ability Is Fixed Have Larger Racial Achievement Gaps and Inspire Less Student Motivation in Their Classes. Sci. Adv. 5 (2), eaau4734. doi:10.1126/sciadv.aau4734

Casper, A. M., Eddy, S. L., and Freeman, S. (2019). True Grit: Passion and Persistence Make an Innovative Course Design Work. Plos Biol. 17 (7), e3000359. doi:10.1371/journal.pbio.3000359

Chetty, R., and Hendren, N. (2018). The Impacts of Neighborhoods on Intergenerational Mobility I: Childhood Exposure Effects*. Q. J. Econ. 133 (3), 1107-1162. doi:10.1093/qje/qjy007

Claro, S., Paunesku, D., and Dweck, C. S. (2016). Growth Mindset Tempers the Effects of Poverty on Academic Achievement. Proc. Natl. Acad. Sci. U S A. 113 (31), 8664-8668. doi:10.1073/pnas.1608207113 beyond students at selective, research-intensive universities, which have dominated contemporary DBER studies.

\section{DATA AVAILABILITY STATEMENT}

The original contributions presented in the study are included in the article/Supplementary Material, further inquiries can be directed to the corresponding author.

\section{AUTHOR CONTRIBUTIONS}

SS had written the first draft and other co-authors equally contributes to revising the draft.

\section{ACKNOWLEDGMENTS}

Shima Salehi acknowledges Stanford's IDEAL initiative. Cissy J. Ballen acknowledges NSF DBI-1919462 and DUE-2011995.

Cohen, G. L., Steele, C. M., and Ross, L. D. (1999). The Mentor's Dilemma: Providing Critical Feedback across the Racial Divide. Pers Soc. Psychol. Bull. 25 (10), 1302-1318. doi:10.1177/0146167299258011

Cooper, K. M., Downing, V. R., and Brownell, S. E. (2018). The Influence of Active Learning Practices on Student Anxiety in Large-Enrollment College Science Classrooms. Int. J. STEM Educ. 5 (1), 23. doi:10.1186/s40594-0180123-6

Cotten, S. R., and Wilson, B. (2006). Student-faculty Interactions: Dynamics and Determinants. High Educ. 51 (4), 487-519. doi:10.1007/s10734-004-1705-4

Dallimore, E. J., Hertenstein, J. H., and Platt, M. B. (2013). Impact of Cold-Calling on Student Voluntary Participation. J. Manage. Educ. 37 (3), 305-341. doi:10.1177/1052562912446067

Driessen, E. P., Knight, J., Smith, M., and Ballen, C. J. (2020). Demystifying the Meaning of Active Learning in Post-Secondary Biology Education. CBE-Life Sci. Educ. 19 (4), ar52. In press. doi:10.1187/cbe.20-04-0068

Dunlosky, J., Rawson, K. A., Marsh, E. J., Nathan, M. J., and Willingham, D. T. (2013). Improving Students' Learning with Effective Learning Techniques: Promising Directions from Cognitive and Educational Psychology. Psychol. Sci. Public Interest 14, 4-58. doi:10.1177/ 1529100612453266

E. Margolis (Editor) (2001). The Hidden Curriculum in Higher Education (London: Psychology Press).

Ericsson, K. A., Krampe, R. T., and Tesch-Romer, C. (1993). The Role of Deliberate Practice in the Acquisition of Expert Performance. Psychol. Rev. 100 (3), 363-406. doi:10.1037/0033-295x.100.3.363

Fahle, E. M., Reardon, S. F., Kalogrides, D., Weathers, E. S., and Jang, H. (2020). Racial Segregation and School Poverty in the United States, 1999-2016. Race Soc. Probl. 12 (1), 42-56. doi:10.1007/s12552-019-09277-w

Feldman, J. (2018). Grading for Equity: What it Is, Why it Matters, and How it Can Transform Schools and Classrooms. Thousand Oaks: Corwin Press.

Freeman, S., Eddy, S. L., McDonough, M., Smith, M. K., Okoroafor, N., Jordt, H., et al. (2014). Active Learning Increases Student Performance in Science, Engineering, and Mathematics. Proc. Natl. Acad. Sci. U S A. 111 (23), 8410-8415. doi:10.1073/pnas.1319030111

Fullilove, R. E., and Treisman, P. U. (1990). Mathematics Achievement Among African American Undergraduates at the university of California, Berkeley: An Evaluation of the Mathematics Workshop Program. J. Negro Educ. 59 (3), 463-478. doi:10.2307/2295577

Good, C., Rattan, A., and Dweck, C. S. (2012). Why Do Women Opt Out? Sense of Belonging and Women's Representation in Mathematics. J. Pers Soc. Psychol. 102, 700-717. doi:10.1037/a0026659 
Haak, D. C., HilleRisLambers, J., Pitre, E., and Freeman, S. (2011). Increased Structure and Active Learning Reduce the Achievement gap in Introductory Biology. Science 332 (6034), 1213-1216. doi:10.1126/science.1204820

Harrison, C., and Tanner, K. D. (2018). Language Matters: Considering Microaggressions in Science. CBE Life Sci. Educ. 17 (1), fe4. doi:10.1187/ cbe.18-01-0011

Jack, A. A. (2019). The Privileged Poor: How Elite Colleges Are Failing Disadvantaged Students. Cambridge: Harvard University Press.

Jensen, J. L., McDaniel, M. A., Woodard, S. M., and Kummer, T. A. (2014). Teaching to the Test or Testing to Teach: Requiring Higher Order Thinking Skills Encourages Greater Conceptual Understanding. Educ. Psychol. Rev. 26, 1-23. doi:10.1007/s10648-013-9248-9

Kanim, S., and Cid, X. C. (2020). Demographics of Physics Education Research. Phys. Rev. Phys. Educ. Res. 16 (2), 020106. doi:10.1103/ physrevphyseducres.16.020106

Kornell, N., and Bjork, R. A. (2007). The Promise and Perils of Self-Regulated Study. Psychon. Bull. Rev. 14 (2), 219-224. doi:10.3758/BF0319405510.3758/ bf03194055

Lin-Siegler, X., Ahn, J. N., Chen, J., Fang, F.-F. A., and Luna-Lucero, M. (2016). Even Einstein Struggled: Effects of Learning about Great Scientists' Struggles on High School Students' Motivation to Learn Science. J. Educ. Psychol. 108 (3), 314-328. doi:10.1037/edu0000092

McDaniel, M. A., Friedman, A., and Bourne, L. E. (1978). Remembering the Levels of Information in Words. Mem. Cogn. 6, 156-164. doi:10.3758/ bf03197441

Meaders, C. L., Lane, A. K., Morozov, A. I., Shuman, J. K., Toth, E. S., Stains, M., et al. (2020). Undergraduate Student Concerns in Introductory Stem Courses: What They Are, How They Change, and what Influences Them. J. STEM Educ Res. 3 (2), 195-216. doi:10.1007/s41979-020-00031-1

Morgan, M. K., Clarke, R. M., Weidmann, M., Laidlaw, J., and Law, A. (2007). How Assessment Drives Learning in Neurosurgical Higher Training. J. Clin. Neurosci. 14, 349-354. doi:10.1016/j.jocn.2005.12.011

Morris, C. D., Bransford, J. D., and Franks, J. J. (1977). Levels of Processing versus Transfer Appropriate Processing. J. Verbal Learn. Verbal Behav. 16, 519-533. doi:10.1016/s0022-5371(77)80016-9

National Academies of Sciences Medicine, E (2016). Barriers and Opportunities for 2-year and 4-year Stem Degrees: Systemic Change to Support Students' Diverse Pathways. Washington: National Academies Press.

National Research Council (2012). Discipline-based Education Research: Understanding and Improving Learning in Undergraduate Science and Engineering. Washington: National Academies Press.

Nicol, D. J., and Boyle, J. T. (2003). Peer Instruction versus Class-wide Discussion in Large Classes: A Comparison of Two Interaction Methods in the Wired Classroom. Stud. Higher Educ. 28, 457-473. doi:10.1080/0307507032000122297

Nielsen, K. L., Hansen-Nygård, G., and Stav, J. B. (2012). Investigating Peer Instruction: How the Initial Voting Session Affects Students' Experiences of Group Discussion. ISRN Educ. 2012, 1-8. doi:10.5402/2012/290157

Powers, J. T., Cook, J. E., Purdie-Vaughns, V., Garcia, J., Apfel, N., and Cohen, G. L. (2016). Changing Environments by Changing Individuals: The Emergent Effects of Psychological Intervention. Psychol. Sci. 27 (2), 150-160. doi:10.1177/0956797615614591

Preszler, R. W., Dawe, A., Shuster, C. B., and Shuster, M. (2007). Assessment of the Effects of Student Response Systems on Student Learning and Attitudes over a Broad Range of Biology Courses. CBE Life Sci. Educ. 6, 29-41. doi:10.1187/cbe.06-09-0190

Quinn, T. (2013). "On Grades and Grading: Supporting Student Learning through a More Transparent and Purposeful Use of Grades," in Chapter 5: Determining Summative Grades (Lanham: R\&L Education).

Rath, K. A., Peterfreund, A. R., Xenos, S. P., Bayliss, F., and Carnal, N. (2007). Supplemental Instruction in Introductory Biology I: Enhancing the Performance and Retention of Underrepresented Minority Students. CBE Life Sci. Educ. 6 (3), 203-216. doi:10.1187/cbe.06-10-0198

Rivers, E. (2017). Women, Minorities, and Persons with Disabilities in Science and Engineering. Alexandria: National Science Foundation.

Rowe, M. B. (1969). Science, Silence, and Sanctions. Sci. Child. 6, 11-13.
Salehi, S., Burkholder, E., Lepage, G. P., Pollock, S., and Wieman, C. (2019). Demographic Gaps or Preparation Gaps? The Large Impact of Incoming Preparation on Performance of Students in Introductory Physics. Phys. Rev. Phys. Educ. Res. 15 (2), 020114. doi:10.1103/ physrevphyseducres. 15.020114

Salehi, S., Cotner, S., and Ballen, C. J. (2020). Variation in Incoming Academic Preparation: Consequences for Minority and First-Generation Students. Front. Educ. 5, 552364, 2020 . Frontiers Media SA. doi:10.3389/feduc.2020.552364

Schwartz, D. L., Cheng, K. M., Salehi, S., and Wieman, C. (2016). The Half Empty Question for Socio-Cognitive Interventions. J. Educ. Psychol. 108 (3), 397-404. doi:10.1037/edu0000122

Seymour, E., and Hunter, A. B. (2019). Talking about Leaving Revisited. New York, NY: Springer.

Smith, B. (2013). Mentoring At-Risk Students through the Hidden Curriculum of Higher Education. Washington: Lexington Books.

Sue, D. W. (2010). Microaggressions in Everyday Life: Race, Gender, and Sexual Orientation. Hoboken: John Wiley \& Sons.

Theobald, E. J., Hill, M. J., Tran, E., Agrawal, S., Arroyo, E. N., Behling, S., et al. (2020a). Active Learning narrows Achievement Gaps for Underrepresented Students in Undergraduate Science, Technology, Engineering, and Math. PNAS March 24, 2020117 (12), 6476-6483. doi:10.1628/zthk-2020-0019

Theobald, E. J., Hill, M. J., Tran, E., Agrawal, S., Arroyo, E. N., Behling, S., et al. (2020b). Active Learning narrows Achievement Gaps for Underrepresented Students in Undergraduate Science, Technology, Engineering, and Math. Proc. Natl. Acad. Sci. U S A. 117 (12), 6476-6483. doi:10.1073/pnas.1916903117

Thomas, A. K., and McDaniel, M. A. (2007). Metacomprehension for Educationally Relevant Materials: Dramatic Effects of Encoding-Retrieval Interactions. Psychon. Bull. Rev. 14, 212-218. doi:10.3758/bf03194054

Thompson, S., Hebert, S., Berk, S., Brunelli, R., Creech, C., Drake, A. G., et al. (2020). A Call for Data-Driven Networks to Address Equity in the Context of Undergraduate Biology. CBE-Life Sci. Educ. 19 (4), mr2, 2020 . (In press). doi:10.1187/cbe.20-05-0085

Willoughby, T., Wood, E., McDermott, C., and McLaren, J. (2000). Enhancing Learning through Strategy Instruction and Group Interaction: Is Active Generation of Elaborations Critical. Appl. Cognit. Psychol. 14, 19-30. doi:10.1002/(sici)1099-0720(200001)14:1<19:aid-acp619>3.0.co;2-4

Wood, E., Willoughby, T., Kaspar, V., and Idle, T. (1994). Enhancing Adolescents' Recall of Factual Content: the Impact of provided versus Self-Generated Elaborations. Albta J. Educ. Res. 40, 57-65.

Wormald, B. W., Schoeman, S., Somasunderam, A., and Penn, M. (2009). Assessment Drives Learning: an Unavoidable Truth. Anat. Sci. Educ. 2, 199-204. doi:10.1002/ase.102

Yeager, D. S., Romero, C., Paunesku, D., Hulleman, C. S., Schneider, B., Hinojosa, C., et al. (2016). Using Design Thinking to Improve Psychological Interventions: The Case of the Growth Mindset during the Transition to High School. J. Educ. Psychol. 108 (3), 374-391. doi:10.1037/edu0000098

Conflict of Interest: The authors declare that the research was conducted in the absence of any commercial or financial relationships that could be construed as a potential conflict of interest.

Publisher's Note: All claims expressed in this article are solely those of the authors and do not necessarily represent those of their affiliated organizations, or those of the publisher, the editors and the reviewers. Any product that may be evaluated in this article, or claim that may be made by its manufacturer, is not guaranteed or endorsed by the publisher.

Copyright $\odot 2021$ Salehi, Ballen, Trujillo and Wieman. This is an open-access article distributed under the terms of the Creative Commons Attribution License (CC BY). The use, distribution or reproduction in other forums is permitted, provided the original author(s) and the copyright owner(s) are credited and that the original publication in this journal is cited, in accordance with accepted academic practice. No use, distribution or reproduction is permitted which does not comply with these terms. 